\title{
Originals
}

\section{Impairment of diastolic function in middle-aged Type 1 (insulin-dependent) and Type 2 (non-insulin-dependent) diabetic patients free of cardiovascular disease}

\author{
M. Uusitupa ${ }^{1}$, J.Mustonen ${ }^{1}$, M.Laakso ${ }^{1}$, P. Vainioº ${ }^{2}$, E.Länsimies ${ }^{2}$, S. Talwar ${ }^{1,3}$ and K. Pyörälä1 $^{1}$ \\ Departments of ${ }^{1}$ Medicine and ${ }^{2}$ Clinical Physiology, Kuopio University Central Hospital, Kuopio, Finland and \\ ${ }^{3}$ Memorial Hospital, Hastings, New Zealand
}

Summary. Left ventricular systolic and diastolic function was studied using systolic time intervals and echocardiography in 19 male and 17 female patients with Type 1 (insulin-dependent) diabetes, 24 male and 15 female patients with Type 2 (non-insulin-dependent) diabetes and 24 male and 24 female control subjects. The subjects for the present study were selected from a population based study in which 117 Type 1 and 510 Type 2 diabetic patients and 649 non-diabetic subjects were originally examined. After exclusions, none of the subjects had any evidence of coronary heart disease, hypertension or other diseases known to affect left ventricular function. There were no consistent differences in systolic time intervals or echocardiographic variables of systolic function between patients with Type 1 diabetes and non-diabetic control subjects; but patients with Type 2 diabetes showed an increased fractional shortening. Female patients with Type 2 diabetes showed an increased left ventricular mass not explicable by hypertension. Isovolumic relaxation period was longer in male $(86 \pm 3 \mathrm{~ms}$; mean $\pm S E M)$ and female patients $(84 \pm 6 \mathrm{~ms})$ with Type 2 diabetes than in male
$(76 \pm 3 \mathrm{~ms} ; p<0.05)$ and female $(71 \pm 3 \mathrm{~ms} ; p<0.05)$ control subjects. Peak diastolic filling rate was lower in female patients with Type 1 diabetes $(12.8 \pm 0.8 \mathrm{~cm} / \mathrm{s}, p<0.05)$ and in male $(11.5 \pm 0.8 \mathrm{~cm} / \mathrm{s} ; \quad p<0.01)$ and female patients $(11.5 \pm 0.6 \mathrm{~cm} / \mathrm{s} ; p<0.001)$ with Type 2 diabetes as compared to male $(14.4 \pm 0.7 \mathrm{~cm} / \mathrm{s})$ and female $(14.9 \pm 0.5 \mathrm{~cm} / \mathrm{s})$ control subjects. In male patients with Type 1 diabetes the respective value $(12.7 \pm 0.6 \mathrm{~cm} / \mathrm{s})$ did not differ significantly from that in male control subjects. Altogether 14 diabetic patients $(26 \%)$ showed an abnormal low peak diastolic filling rate. The impaired diastolic filling among diabetic patients did not show any relationship to the duration and metabolic control of diabetes or the presence of microangiopathy, but a weak correlation was found between the peak diastolic filling rate and the diminution of heart rate variation suggestive of the presence of diabetic autonomic neuropathy.

Key words: Diabetic heart muscle disease, diabetic cardiomyopathy, diastolic function, autonomic neuropathy, diabetes.
An increased occurrence of coronary heart disease and hypertension are important determinants of excess cardiovascular morbidity and mortality of diabetic patients; they also partly explain the excess occurrence of cardiac failure in diabetic patients [1]. During the last 10 to 15 years a number of pathoanatomic [2-10], clinical $[2,3,10]$ and epidemiological [11] studies have given evidence about the existence of a specific diabetic heart muscle disease which has been suggested to be in part responsible for the high incidence of cardiac failure in diabetic patiens [11].

Some echocardiographic studies carried out on juvenile onset, Type 1 (insulin-dependent) diabetic patients have shown an impairment in left ventricular systolic function [12,13], whereas in other studies systolic function has been normal. But various abnormalities in diastolic function, e.g. prolonged isovolumic relaxation period, delayed mitral valve opening and impairment in rapid diastolic filling have been characteristic findings [14-19]. Furthermore, it has been suggested that diastolic abnormalities may be an early manifestation of a specific diabetic heart muscle disease [17]. A relationship between cardiac dysfunction and the duration of diabetes or the presence of microangiopathic complications has been reported by some authors $[15,17$, $18]$, but others have failed to confirm this $[14,19]$. In a study on Type 1 diabetic patients based on equilibrium radionuclide angiocardiography an abnormal diastolic filling was found to be associated with diabetic autonomic neuropathy [20]. Numerous studies with systolic and diastolic time intervals have also been performed on diabetic patients to evaluate left ventricular systolic $[14,16,21-27]$ and diastolic function $[14,24]$, but the results have been quite contradictory. Furthermore, studies on cardiac dysfunction in diabetes deal largely with insulin-dependent diabetes, although reports on 
systolic $[14,21,22,27]$ and diastolic dysfunction $[10,28]$ in Type 2 (non-insulin-dependent) diabetic patients are also available. Because asymptomatic coronary heart disease may cause both systolic and diastolic dysfunction, its concomitant occurrence remains the most important confounding factor in studies attempting to resove the existence and significance of diabetic heart muscle disease [29]. We have carried out a study on left ventricular function in a group of patients with Type 1 and Type 2 diabetes and non-diabetic control subjects free of any cardiovascular disease known to affect myocardial function. In this paper we report results concerning left ventricular systolic and diastolic function examined by systolic time intervals, apexcardiography and echocardiography.

\section{Subjects and methods}

\section{Subjects}

The subjects for the present study were selected from the study population of a larger study on diabetic patients and non-diabetic control subjects carried out at our department in 1982-1983 [30]. In connection with this study 117 patients with Type 1 and 510 patients with Type 2 diabetes and 649 non-diabetic subjects aged 45-64 years living in the Kuopio University Central Hospital district were examined. The diabetic patients had originally been identified on the basis of the register of the Social Insurance Institution on diabetic patients receiving drug reimbursement. In all of them the diagnosis of diabetes had been made after the age of 30 years. The diagnosis of diabetes was confirmed according to the diagnostic criteria recommended by WHO Expert Committee on Diabetes Mellitus [31]. Patients on insulin treatment in whom glucagon stimulated C-peptide secretion remained lower than $0.60 \mathrm{nmol} / \mathrm{l}$ were regarded as insulindependent [32].

Non-diabetic control subjects were randomly selected from the population registers containing all subjects aged 45-64 of the Kuopio University Central Hospital district.

Diabetic patients and non-diabetic control subjects were identified from the initial study population by the following exclusion criteria:

1. History of previous myocardial infarction, angina pectoris or other symptomatic coronary heart disease

2. The presence of "ischaemic" electrocardiographic abnormalities (Q-QS changes; Minnesota code 1.1-3, ST-segment depression; Minnesota code 4.1-3, T-wave abnormalities; Minnesota code 5.1-3, left and right bundle branch block; Minnesota codes 7.1 and 7.2 and atrial fibrillation; Minnesota code 8.3)

3. Valvular and other known heart disease

4. Cerebrovascular or peripheral arterial disease

5. Arterial hypertension (use of antihypertensive drugs or systolic blood pressure $\geqq 160 \mathrm{~mm} \mathrm{Hg}$ or diastolic blood pressure $\geqq 95 \mathrm{~mm} \mathrm{Hg}$ ) 6. Drug therapy affecting cardiac function

7. Thyroid disease, chronic alcoholism or any disease known to affect cardiac function

After these exclusions, 43 male and 39 female diabetic patients and 137 male and 152 female control subjects were eligible for further evaluation. In order to study an equal number of diabetic patients in both diabetic groups and control subjects, 33 male and 30 female control subjects were randomly selected from those fulfilling the inclusion criteria. After exclusions of subjects in whom new cardiovascular disease developed since the first examination, 19 male Type 1 , 24 male Type 2, 17 female Type 1 and 15 female Type 2 diabetic patients and 24 male and 24 female control subjects were included into final analyses.

\section{Methods}

Medical history consisted of a history of previous cardiovascular diseases and use of drugs. Chest pain and claudication history was obtained by the Rose's cardiovascular questionnaire [33]. Clinical examination included the palpation and auscultation of the heart and large arteries and the measurement of blood pressure. A 12-lead electrocardiogram was recorded and analysed according to the Minnesota code [34].

Bicycle ergometer test. A bicycle exercise test was performed on all diabetic and control subjects in the sitting position on an electrically braked bicycle ergometer (Ergometer 380, Siemens Elema, Solna, Sweden) starting at a work load of $50 \mathrm{~W}$. The work load was increased stepwise with $30 \mathrm{~W}$ for women and with $50 \mathrm{~W}$ for men at $3 \mathrm{~min} /$ intervals. The exercise test was continued until $85 \%$ of the predicted maximum heart rate was attained or to the subjective maximum. The criterion for an abnormal exercise electrocardiogram was horizontal or down-sloped ST segment depression of $0.1 \mathrm{mV}$ or more persisting for $80 \mathrm{~ms}$ after J-point of QRS complex or a T wave inversion during or after exercise.

From a chest X-ray the signs of left ventricular failure in pulmonary circulation were recognised.

Heart rate variation during deep breathing and the change in systolic blood pressure during tilting were used for the evaluation of autonomic nervous function [35].

Systolic time intervals and apexcardiograms were recorded with Siemens Elema Mingograph 34 (Solna, Sweden) at a paper speed of $100 \mathrm{~mm} / \mathrm{s}$. Systolic time intervals were recorded in the supine position and apexcardiogram in the left lateral decubitus position. Lead II was used for the identification of Q-wave. Phonocardiogram was recorded with EMT $25 \mathrm{C}$ microphone $(200 \mathrm{~Hz})$ from second intercostal space right-sided parasternally. Carotid pulse and apex curves were recorded by EMT-510C-transducer connected via a polyethylene tube to a funnel-shaped pickup, which was manually held over the carotid artery or left ventricular apex. Simultaneous recordings were shown by a monitor to get high quality recordings. Ten consecutive cardiac cycles were recorded. All measurements were made by using $x$-y-digitiser (BitPadOne, Summagraphics, Fairfield, Connecticut, USA) which was connected with Eclipse S/130 computer (Eclipse System, Data General, Southboro, Massachusetts, USA). The mean values of ten cardiac cycles were regarded as results. The following variables were measured: the interval between the QRS-complexes of ECG (R-R) interval, electromechanical systole and left ventricular ejection time. From the measured variables pre-ejection period, and heart rate corrected values for pre-ejection period, and left ventricular ejection time as well as the ratio of preejection period to left ventricular ejection time were calculated according to Weissler et al. [36]. From the apexcardiogram the ratio of the height of $\mathrm{A}$-wave to the total height of apexcardiogram $(\mathrm{A} / \mathrm{H}-$ ratio) was calculated [37].

Echocardiography. Echocardiograms were recorded with a sector electronic scanning type ultrasound heart diagnostic system (Toshiba Sonolayer Model SSH-40A, Tochigi-Ken, Japan) using a transducer (Toshiba PSA-24 B) with a 90 degree sector scan angle and a frequency of $2.4 \mathrm{MHz}$. The M-mode echocardiograms, electrocardiograms and phonocardiograms were recorded simultaneously with a Toshiba line scan (LSR-20B) on the photosensitive paper at the paper speed of $100 \mathrm{~mm} / \mathrm{s}$. Subjects were examined in the left lateral decubitus position. Two dimensional scans were used in order to search the optimal level for M-mode recording. Echocardiograms of the left ventricular cavity were recorded when the interventricular septum and left ventricular posterior wall were clearly seen just below the edge of the anterior mitral leaflet. All measurements were made using the $x$-y-digitiser (resolution $0.1 \mathrm{~mm}$ ) interfaced to the computer. Five consecutive or nearly consecutive cycles were measured and the means were recorded as results. All recordings and measurements were made by the same investigator according to the recommendations of the American Society of Echocardiography 
[38] without knowledge of clinical status. Isovolumic relaxation period was measured from the onset of aortic component of second heart sound to the mitral valve opening.

From the variables measured the following calculations were made:

fractional shortening $(F S)=($ LVEDD-LVESD $) /$ LVEDD

mean rate of circumferential shortening

$($ VCF $)=($ LVEDD-LVESD $) /($ LVEDD $\times$ LVET $)$

left ventricular mass/body surface area $\left(\mathrm{g} / \mathrm{m}^{2}\right)=$

$\left[(\text { LVEDD }+ \text { SEPTUM }+ \text { LVPW })^{3}-(\text { LVESD })^{3}\right] \times 1.05$

body surface area

LVEDD = left ventricular end-diastolic diameter

LVESD $=$ left ventricular end-systolic diameter

LVET = left ventricular ejection time

SEPTUM $=$ thickness of interventricular septum

LVPW $=$ thickness of left ventricular posterior wall

Digitisation of M-mode left ventricular recordings was made according to the modified technique used by Griffiths et al. [39]. A cross-hair sight was used to record the leading edges of the septal endocardium and of the endocardium of the left ventricular posterior wall. The Q-waves in electrocardiogram before and after digitised left ventricular systole and diastole $\left(\mathrm{Q}_{1}\right.$ and $\left.\mathrm{Q}_{2}\right)$ and the onset of the aortic component of the second heart sound $\left(\mathrm{A}_{2}\right)$ in phonocardiogram were served as time makers. The computer calculated the size and rate of change of ventricular cavity. The following variables were measured: R-R interval, peak rate of decrease in left ventricular dimension in systole (peak systolic ejection rate) and peak rate of increase in left ventricular dimension in diastole (peak diastolic filling rate).

Radionuclide angiocardiography for evaluation of systolic function was performed on each subject at rest, during and after exercise.

Thallium scintigraphy was performed on subjects who showed $\geqq 1.0 \mathrm{mV}$ ST-segment depression at bicycle ergometer test $(n=3)$ or whose left ventricular ejection fraction measured by radionuclide angiocardiography decreased during exercise $(n=18)$ to exclude subjects with asymptomatic coronary heart disease. Two patients with an abnormal ST-segment depression and one patient with abnormal left ventricular ejection fraction response to exercise refused to undergo thallium scintigraphy.

Blood glucose was analysed by a glucose dehydrogenase method
(Merck, Darmstadt, FRG) and glucosylated haemoglobin $\mathrm{A}_{1}$ by an affinity chromatography (Isolab Inc, Akron, Ohio, USA).

Serum total cholesterol and triglycerides were analysed enzymatically. Serum HDL-cholesterol was also analysed enzymatically after precipitation of LDL and VLDL with dextran sulphate and $\mathrm{MgCl}_{2}$ [40].

Routine laboratory methods were used for the determinations of serum thyroxine, creatinine, electrolytes and urinary albumin.

Approval for the study was given by the Ethical Committee of the University of Kuopio. Informed consent was obtained from each subject.

\section{Statistical analysis}

Analysis of variance (ANOVA) and Student's t-test for unpaired data were used in comparisons of the mean values of the diabetic and control groups. Pearson's linear correlation coefficients were calculated for some pairs of continuous variables. $\chi^{2}$-test was used in comparisons concerning frequency differences.

\section{Results}

\section{Clinical characteristics and laboratory data}

Table 1 shows clinical characteristics and laboratory data of the study groups. There were no significant differences in the mean ages between either group of diabetic patients and non-diabetic control subjects. The duration of diabetes was longer in Type 1 than in Type 2 diabetic patients. Both male and female patients with Type 1 diabetes were leaner than nondiabetic control subjects. On the other hand, female patients with Type 2 diabetes were more obese than female control subjects. Systolic blood pressure level in the two groups of diabetic patients did not differ significantly from that seen in control subjects, but diastolic blood pressure level was lower in male patients with Type 1 and Type 2 diabetes than in male control subjects. The prevalence of retinopathy tended

Table 1. Clinical characteristics of the study groups

\begin{tabular}{|c|c|c|c|c|c|c|c|c|c|c|c|c|}
\hline \multirow[b]{3}{*}{ Age (years) } & \multicolumn{6}{|l|}{ Men } & \multicolumn{6}{|l|}{ Women } \\
\hline & \multicolumn{2}{|c|}{$\begin{array}{l}\text { Control } \\
\text { subjects } \\
(n=24)\end{array}$} & \multicolumn{2}{|c|}{$\begin{array}{l}\text { Patients } \\
\text { with Type } 1 \\
\text { diabetes } \\
(n=19)\end{array}$} & \multicolumn{2}{|c|}{$\begin{array}{l}\text { Patients } \\
\text { with Type } 2 \\
\text { diabetes } \\
(n=24)\end{array}$} & \multicolumn{2}{|c|}{$\begin{array}{l}\text { Control } \\
\text { subjects } \\
(n=24)\end{array}$} & \multicolumn{2}{|c|}{$\begin{array}{l}\text { Patients } \\
\text { with Type } 1 \\
\text { diabetes } \\
(n=17)\end{array}$} & \multicolumn{2}{|c|}{$\begin{array}{l}\text { Patients } \\
\text { with Type } 2 \\
\text { diabetes } \\
(n=15)\end{array}$} \\
\hline & 55.4 & \pm 1.2 & 54.3 & \pm 1.1 & 57.2 & \pm 1.3 & 55.0 & \pm 1.2 & 55.2 & \pm 1.4 & 56.7 & \pm 1.3 \\
\hline Duration of diabetes (years) & & - & 16.5 & \pm 2.2 & 9.9 & \pm 0.9 & & - & 16.5 & \pm 2.1 & 9.7 & \pm 1.0 \\
\hline Body mass index $\left(\mathrm{kg} / \mathrm{m}^{2}\right)$ & 26.2 & \pm 0.5 & 23.6 & $\pm 0.5^{\mathrm{c}}$ & 25.0 & \pm 0.5 & 26.0 & \pm 1.0 & 23.3 & $\pm 0.8^{\mathrm{a}}$ & 29.7 & $\pm 1.4^{\mathrm{a}}$ \\
\hline Systolic blood pressure ( $\mathrm{mm} \mathrm{Hg}$ ) & 140 & \pm 3 & 138 & \pm 3 & 137 & \pm 3 & 148 & \pm 4 & 147 & \pm 4 & 147 & \pm 5 \\
\hline Diastolic blood pressure (mm Hg) & 87 & \pm 1 & 81 & $\pm 1^{b}$ & 82 & $\pm 2^{\mathrm{a}}$ & 85 & \pm 2 & 81 & \pm 2 & 84 & \pm 2 \\
\hline Prevalence of retinopathy $(\%)$ & & - & \multicolumn{2}{|c|}{$11(58)$} & \multicolumn{2}{|c|}{$4(17)$} & & - & \multicolumn{2}{|c|}{$10(59)$} & \multicolumn{2}{|c|}{$4(27)^{-2}$} \\
\hline Heart rate (beats $/ \mathrm{min}$ ) & 64.2 & \pm 1.7 & 66.5 & \pm 2.5 & 72.7 & $\pm 2.4^{\mathrm{b}}$ & 67.1 & \pm 1.8 & 76.1 & $\pm 3.4^{\mathrm{a}}$ & 79.0 & $\pm 3.0^{\mathrm{b}}$ \\
\hline $\begin{array}{l}\text { Heart rate variation during } \\
\text { hyperventilation (beats/min) }\end{array}$ & 15.8 & \pm 1.4 & 12.5 & \pm 1.7 & 13.4 & \pm 1.9 & 17.4 & \pm 1.6 & 13.0 & \pm 1.6 & 12.7 & \pm 2.0 \\
\hline $\begin{array}{l}\text { Decrease of systolic blood } \\
\text { pressure during tilting }(\mathrm{mm} \mathrm{Hg})\end{array}$ & -3.2 & \pm 3.1 & -11.5 & \pm 2.8 & -10.1 & \pm 3.4 & -12.8 & \pm 2.8 & -11.6 & \pm 4.3 & -4.5 & \pm 4.8 \\
\hline Blood glucose $(\mathrm{mmol} / \mathrm{l})$ & 4.8 & \pm 0.1 & 9.7 & \pm 0.7 & 11.7 & \pm 0.6 & 4.6 & \pm 0.1 & 10.2 & \pm 1.0 & 11.7 & \pm 1.2 \\
\hline Glucohaemoglobin $\mathrm{A}_{1}(\%)$ & 6.1 & \pm 0.1 & 9.8 & \pm 0.5 & 9.8 & \pm 0.4 & 6.6 & \pm 0.2 & 10.6 & \pm 0.5 & 9.6 & \pm 0.4 \\
\hline Cholesterol $(\mathrm{mmol} / \mathrm{l})$ & 6.93 & \pm 0.25 & 6.41 & \pm 0.33 & 6.43 & \pm 0.28 & 7.15 & \pm 0.33 & 7.07 & \pm 0.32 & 7.18 & \pm 0.49 \\
\hline Triglycerides $(\mathrm{mmol} / \mathrm{l})$ & 1.33 & \pm 0.13 & 1.07 & \pm 0.09 & 1.42 & \pm 0.17 & 1.23 & \pm 0.14 & 1.00 & \pm 0.1 & 2.21 & \pm 0.48 \\
\hline HDL-cholesterol (mmol/l) & 1.34 & \pm 0.06 & 1.54 & \pm 0.11 & 1.38 & \pm 0.07 & 1.57 & \pm 0.11 & 1.95 & $\pm 0.08^{b}$ & 1.59 & \pm 0.10 \\
\hline
\end{tabular}

${ }^{\mathrm{a}} p<0.05 ;{ }^{\mathrm{b}} p<0.01 ;{ }^{\mathrm{c}} p<0.001$ as compared to the respective control subjects (ANOVA and Student's $t$-test) 
Table 2. Systolic time intervals and $\mathrm{A} / \mathrm{H}$ ratio in apexcardiogram in diabetic and control subjects

\begin{tabular}{|c|c|c|c|c|c|c|c|c|c|c|c|c|}
\hline \multirow[b]{3}{*}{$\begin{array}{l}\text { Pre-ejection } \\
\text { period (ms) }\end{array}$} & \multicolumn{6}{|l|}{ Men } & \multicolumn{6}{|c|}{ Women } \\
\hline & \multicolumn{2}{|c|}{$\begin{array}{l}\text { Control } \\
\text { subjects } \\
(n=24)\end{array}$} & \multicolumn{2}{|c|}{$\begin{array}{l}\text { Patients } \\
\text { with Type } 1 \\
\text { diabetes } \\
(n=19)\end{array}$} & \multicolumn{2}{|c|}{$\begin{array}{l}\text { Patients } \\
\text { with Type } 2 \\
\text { diabetes } \\
(n=24)\end{array}$} & \multicolumn{2}{|c|}{$\begin{array}{l}\text { Control } \\
\text { subjects } \\
\text { diabetes } \\
(n=24)\end{array}$} & \multicolumn{2}{|c|}{$\begin{array}{l}\text { Patients } \\
\text { with Type } 1 \\
\text { diabetes } \\
(n=17)\end{array}$} & \multicolumn{2}{|c|}{$\begin{array}{l}\text { Patients } \\
\text { with Type } 2 \\
(n=15)\end{array}$} \\
\hline & $\begin{array}{r}109 \\
(113\end{array}$ & $\begin{array}{l} \pm 3 \\
\pm 3)\end{array}$ & $\begin{array}{r}103 \\
(130\end{array}$ & $\begin{array}{l} \pm 3 \\
\pm 3)\end{array}$ & $\begin{array}{r}108 \\
(136\end{array}$ & $\begin{array}{l} \pm 3 \\
\pm 3)\end{array}$ & $\begin{aligned} 106 \\
(133\end{aligned}$ & $\begin{array}{l} \pm 2 \\
\pm 2)\end{array}$ & $\begin{array}{r}96 \\
(126\end{array}$ & $\begin{array}{l} \pm 4^{\mathrm{a}} \\
\pm 4)\end{array}$ & $\begin{array}{r}102 \\
(130\end{array}$ & $\begin{array}{l} \pm 3 \\
\pm 4)\end{array}$ \\
\hline $\begin{array}{l}\text { Left ventricular } \\
\text { ejection time (ms) }\end{array}$ & $\begin{array}{r}304 \\
(408\end{array}$ & $\begin{array}{l} \pm 4 \\
\pm 3)\end{array}$ & $\begin{array}{r}302 \\
(417\end{array}$ & $\begin{array}{l} \pm 5 \\
\pm 3)^{\mathrm{a}}\end{array}$ & $\begin{array}{r}292 \\
(409\end{array}$ & $\begin{array}{l} \pm 4^{\mathrm{a}} \\
\pm 3)\end{array}$ & $\begin{array}{r}311 \\
(417\end{array}$ & $\begin{array}{l} \pm 4 \\
\pm 2)\end{array}$ & $\begin{array}{r}306 \\
(424\end{array}$ & $\begin{array}{l} \pm 5 \\
\pm 4)\end{array}$ & $\begin{array}{r}302 \\
(417\end{array}$ & $\begin{array}{l} \pm 6 \\
\pm 4)\end{array}$ \\
\hline $\begin{array}{l}\text { Pre-ejection period/ } \\
\text { Left ventricular ejection time }\end{array}$ & \multicolumn{2}{|c|}{$0.36 \pm 0.01$} & \multicolumn{2}{|c|}{$0.34 \pm 0.01$} & \multicolumn{2}{|c|}{$0.37 \pm 0.01$} & \multicolumn{2}{|c|}{$0.34 \pm 0.01$} & \multicolumn{2}{|c|}{$0.32 \pm 0.01$} & \multicolumn{2}{|c|}{$0.34 \pm 0.01$} \\
\hline A/H-ratio (\%) & 9.6 & \pm 0.5 & 8.6 & \pm 1.0 & 11.0 & \pm 0.6 & 8. & \pm 0.7 & 8.9 & \pm 1.0 & 11.4 & $\pm 0.7^{\mathrm{b}}$ \\
\hline
\end{tabular}

${ }^{\mathrm{a}} p<0.05 ;{ }^{\mathrm{b}} p<0.01 ;{ }^{\mathrm{c}} p<0.001$ as compared to the respective control subjects (ANOVA and Student's $t$-test)

Values corrected for heart rate are given in parentheses. $\mathrm{A} / \mathrm{H}$-ratio $=$ the height of $\mathrm{A}$ wave/the total amplitude of apexcardiogram

to be more common in patients with Type 1 than in those with Type 2 diabetes. Men with Type 2 diabetes and women with Type 1 and Type 2 diabetes showed a higher heart rate than the respective control subjects. Both groups of diabetic patients tended to have lower heart rate variation than non-diabetic control subjects and the differences reached statistical significance when both sexes were analysed together $(p<0.05)$. Systolic blood pressure during orthostatic test did not differ between either group of diabetic patients and nondiabetic control subjects. None of the subjects showed any evidence of pulmonary venous congestion in chest $\mathrm{X}$-ray examination.

The diabetic groups did not differ from each other with respect to glucosylated haemoglobin $\mathrm{A}_{1}$ level. There were no significant differences in serum total cholesterol or triglyceride levels in diabetic and nondiabetic subjects, but HDL-cholesterol was elevated in female patients with Type 1 diabetes.

Serum creatinine levels were similar in each group. No significant differences were found in reported alcohol consumption or smoking between diabetic and control subjects (data not shown).

\section{Systolic time intervals and apexcardiography}

Systolic time intervals and $\mathrm{A} / \mathrm{H}$-ratio in apexcardiography are shown in Table 2. After correction for heart rate, left ventricular ejection time was longer in male patients with Type 1 diabetes than in male control subjects but otherwise no significant differences were observed in men. In women, systolic time intervals after correction for heart rate were similar in diabetic and control subjects, but patients with Type 2 diabetes had a greater $\mathrm{A} / \mathrm{H}$-ratio than the respective female control subjects.

\section{Echocardiographic findings}

Various echocardiographic variables are expressed in Table 3. The left atrial diameters and septal and left ventricular posterior wall thicknesses as well as left ventricular mass were similar in male diabetic patients and control subjects. Similarly, female patients with Type 1 diabetes did not differ from female control subjects in these respects, but female patients with Type 2 diabetes showed a thicker septum and left ventricular posterior wall and an increased left ventricular mass as compared to the female control subjects. Male patients with Type 2 diabetes had a somewhat smaller left ventricular end-systolic diameter than male control subjects, but otherwise no significant differences were found between male diabetic patients and control subjects in left ventricular internal dimensions or systolic function evaluated by echocardiography.

Fractional shortening was greater in female patients with Type 2 diabetes than in the respective control subjects. In addition, the mean velocity of circumferential shortening was increased in female patients with Type 1 and Type 2 diabetes as compared to the female control subjects. When both sexes were analysed together patients with Type 2 diabetes showed a greater fractional shortening $(p<0.01)$, and the mean velocity of circumferential shortening was increased in both Types of diabetes compared to control subjects ( $p<0.01$ for Type 1 and $p<0.001$ for Type 2 diabetes). There were no significant differences in the peak systolic ejection rate between diabetic and control subjects in men or women.

In male patients with Type 2 diabetes the isovolumic relaxation period was longer than in male control subjects. Similarly, women with Type 2 diabetes showed a prolonged isovolumic relaxation period. The peak diastolic filling rate was decreased in male patients with Type 2 diabetes and in both groups of female diabetic patients as compared to the respective control subjects. After combining sexes for the analysis, patients with Type 1 and Type 2 diabetes showed significantly decreased peak diastolic filling rates $(p<0.01$ and $p<0.001$ for Type 1 and Type 2 diabetes respectively). When the mean-2 SD for normal subjects $(10.1 \mathrm{~cm} / \mathrm{s})$ was regarded as the lower normal 
Table 3. Echocardiographic variables in diabetic and control subjects

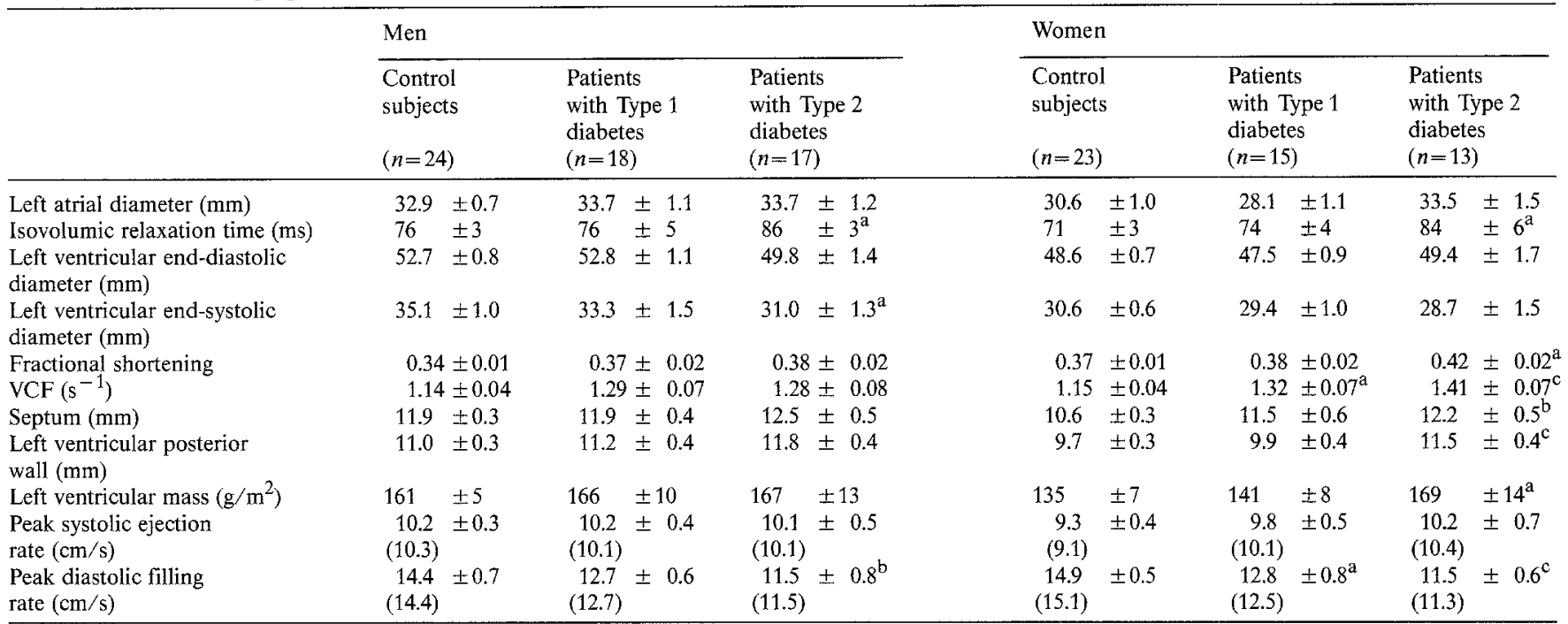

$\mathrm{VCF}=$ mean velocity of circumferential shortening; Values corrected for heart rate are given in parentheses.

${ }^{\mathrm{a}} p<0.05 ;{ }^{\mathrm{b}} p<0.01 ;{ }^{\mathrm{c}} p<0.001$ as compared to the respective control subjects (ANOVA and Student's $t$-test)

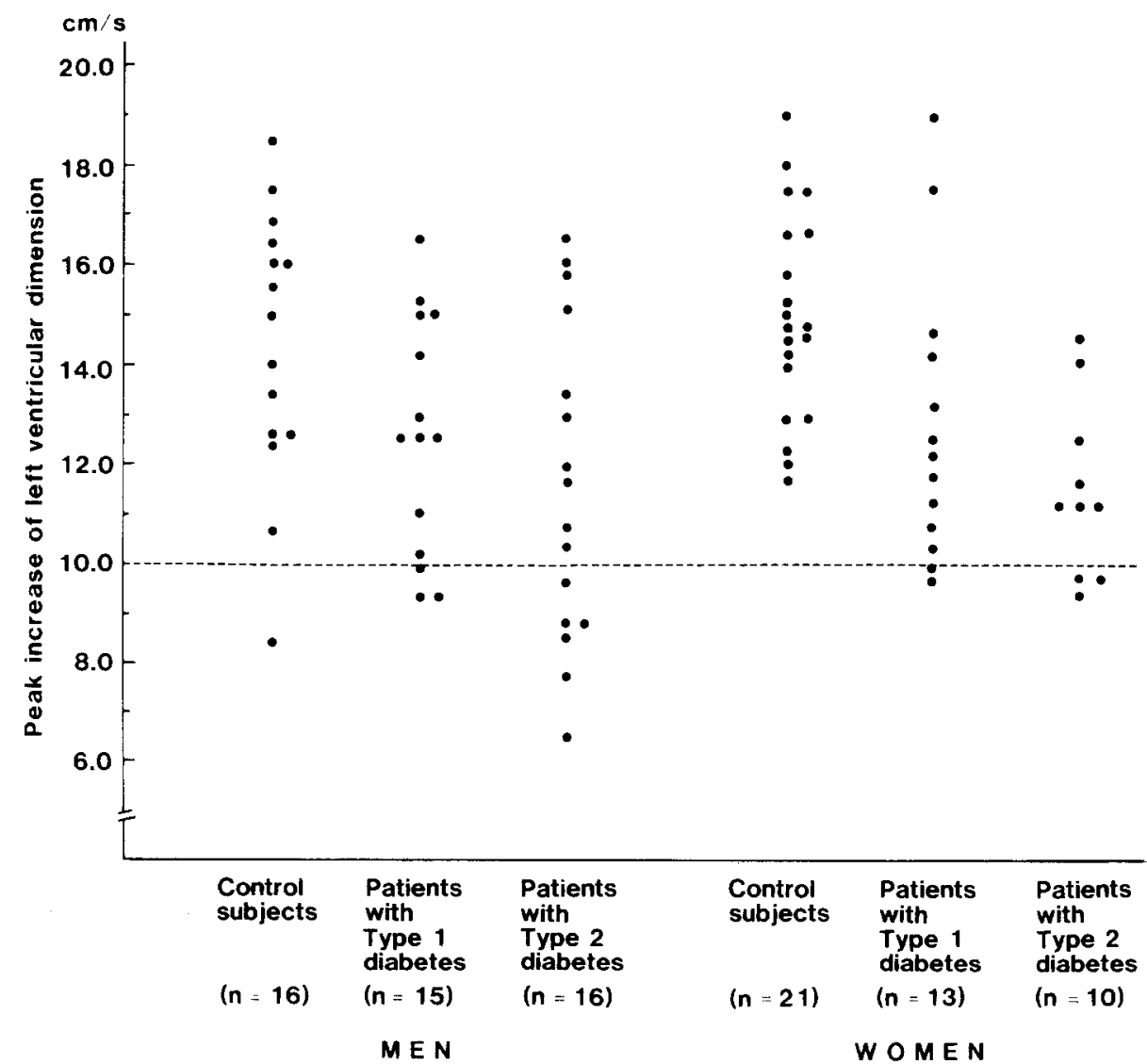

Fig. 1. The peak diastolic filling rate in the two groups of diabetic patients and control subjects by sex. Dotted line (----) indicates the lower normal limit $(10.1 \mathrm{~cm} / \mathrm{s})$ limit of the peak diastolic filling rate, 3 men and 2 women with Type 1 diabetes and 6 men and 3 women with Type 2 diabetes had an abnormal diastolic peak filling rate (Fig. 1). The abnormal filling was significantly more common among diabetic patients than control subjects when both types of diabetes were analysed together combining each sex $\left(\chi^{2}=8.60, p<0.01\right)$.

\section{Contribution of asymptomatic ischaemic heart disease to diastolic dysfunction in diabetic patients}

Among all diabetic patients 5 showed an abnormal exercise ECG. In 3 of them (1 man with Type 1 diabetes, 1 man with Type 2 diabetes, 1 woman with Type 1) on whom myocardial scintigraphy was performed, it was normal. Left ventricular ejection frac- 
tion evaluated by radionuclide angiocardiography decreased during exercise in 19 patients $(5$ men with Type 1 diabetes, 6 men with Type 2 diabetes, 2 women with Type 1 diabetes and 6 women with Type 2 diabetes). None of them had a pathological exercise ECG. In 5 of them thallium scintigraphy showed a perfusion defect suggestive of asymptomatic ischaemic heart disease during exercise but in the rest it was normal. An abnormal diastolic function in echocardiography was observed only in 2 of those 5 patients with a perfusion defect.

Subjects with a perfusion defect did not differ from those with normal thallium scintigraphy with respect to the prevalence of retinopathy ( $40 \%$ vs $46 \%)$, left ventricular peak ejection and peak filling rates or any other echocardiographic variables.

\section{Other factors associated with impaired diastolic filling in diabetic subjects}

Table 4 summarises selected clinical, biochemical and echocardiographic variables in the diabetic patients with normal and abnormal filling rate. Patients with abnormal filling rate did not differ significantly from those with normal filling with respect to the mean age, duration of diabetes, heart rate, blood pressure level, body mass index, the prevalence of retinopathy and metabolic control of diabetes. By contrast, the mean heart rate variation was significantly lower in subjects with abnormal than in those with normal filling $(9.4 \pm 1.7$ vs $14.4 \pm 1.2$ beats $/ \mathrm{min} ; p=0.023)$. No signif icant differences were found in the decrease of systolic blood pressure during orthostatic test between subjects with normal and abnormal filling. The diabetic patients with abnormal filling had a prolonged isovolumic relaxation period ( $93 \pm 5$ vs $77 \pm 3 \mathrm{~ms} ; p<0.01$ ) and a greater left atrial diameter $(37 \pm 1 \mathrm{~mm}$ vs $31 \pm 1 \mathrm{~mm} ; p<0.001)$ than those with normal filling. No significant differences were found in left ventricular internal dimensions, left ventricular mass, fractional shortening or mean rate of circumferential velocity between these two diabetic groups but the peak systolic ejection rate was lower in those with abnormal $(9.3 \pm 0.6 \mathrm{~cm} / \mathrm{s} ; p=0.049)$ than in those with normal filling rate $(10.4 \pm 0.3 \mathrm{~cm} / \mathrm{s})$.

The peak diastolic filling rate showed a low but significant correlation to heart rate variation during hyperventilation $(r=0.22 ; p=0.05)$ and to the decrease in systolic blood pressure in orthostatic test $(r=-0.25 ; p=0.036)$.

\section{Discussion}

Most of the previous studies on left ventricular function in diabetes have been carried out on patients attending diabetic clinics. Furthermore, the majority of
Table 4. Selected clinical, biochemical and echocardiographic variables in diabetic patients with normal and abnormal diastolic peak filling rate

\begin{tabular}{|c|c|c|c|c|}
\hline \multirow[b]{2}{*}{ Age (years) } & \multicolumn{2}{|l|}{$\begin{array}{l}\text { Normal } \\
\text { filling } \\
(n=40)\end{array}$} & \multicolumn{2}{|c|}{$\begin{array}{l}\text { Abnormal } \\
\text { filling } \\
(n=14)\end{array}$} \\
\hline & 55.0 & \pm 0.9 & 57.7 & \pm 1.4 \\
\hline Duration of diabetes (years) & 14.1 & \pm 1.5 & 11.9 & \pm 1.3 \\
\hline Heart rate (beats/min) & 70.7 & \pm 1.9 & 68.4 & \pm 2.6 \\
\hline Systolic blood pressure (mm Hg) & 140 & \pm 2 & 141 & \pm 4 \\
\hline Diastolic blood pressure $(\mathrm{mm} \mathrm{Hg})$ & 82 & \pm 1 & 82 & \pm 2 \\
\hline Body mass index $\left(\mathrm{kg} / \mathrm{m}^{2}\right)$ & 24.0 & \pm 0.6 & 26.5 & \pm 0.7 \\
\hline Prevalence of retinopathy $(\%)$ & 40 & & 43 & \\
\hline Heart rate variation (beats/min) & 14.4 & \pm 1.2 & 9.4 & $\pm 1.7^{\mathrm{a}}$ \\
\hline $\begin{array}{l}\text { Decrease in systolic blood pressure } \\
\text { during tilting }(\mathrm{mm} \mathrm{Hg})\end{array}$ & -12.9 & \pm 4.7 & -8.6 & \pm 2.5 \\
\hline Glucohaemoglobin $\mathrm{A}_{1}(\%)$ & 10.0 & \pm 0.3 & 10.2 & \pm 0.5 \\
\hline Fasting blood glucose (mmol/1) & 10.9 & \pm 0.7 & 10.1 & \pm 0.9 \\
\hline Isovolumic relaxation time (ms) & 77 & \pm 3 & 93 & $\pm 5^{b}$ \\
\hline Left atrial diameter $(\mathrm{mm})$ & 31 & \pm 1 & 37 & $\pm 1^{\mathrm{c}}$ \\
\hline $\begin{array}{l}\text { Left ventricular end-systolic } \\
\text { diameter }(\mathrm{mm})\end{array}$ & 30 & \pm 1 & 32 & \pm 2 \\
\hline $\begin{array}{l}\text { Left ventricular end-diastolic } \\
\text { diameter }(\mathrm{mm})\end{array}$ & 49 & \pm 1 & 50 & \pm 2 \\
\hline Left ventricular mass $\left(\mathrm{g} / \mathrm{m}^{2}\right)$ & 147 & \pm 6 & 153 & \pm 12 \\
\hline Fractional shortening & 0.40 & \pm 0.08 & 0.36 & \pm 0.03 \\
\hline Peak systolic ejection rate $(\mathrm{cm} / \mathrm{s})$ & 10.4 & \pm 0.3 & 9.3 & $\pm 0.6^{\mathrm{a}}$ \\
\hline
\end{tabular}

${ }^{\mathrm{a}} p<0.05$; $^{\mathrm{b}} p<0.01 ;{ }^{\mathrm{c}} p<0.001$ (Student's $t$-test)

patients have had Type 1 diabetes, whereas Type 2 diabetes has gained less attention. In the present study, a well characterised diabetic population including both types of diabetic patients and a comparable nondiabetic population were studied. However, the original diabetic population was not representative as to the patients with mild diabetes treated with diet only [30]. Much effort was given to the selection of the subjects, and only those who showed no evidence of cardiovascular disease were eligible for the closer evaluation. Due to the strict exclusion criteria the diabetic patients showed no abnormalities in serum lipids and their diastolic blood pressure level was even lower than in control subjects. This is in contrast to that found in most previous studies [1] and to that observed in the original study population [30]. As distinct from most previous studies the diabetic patients of the present study were older and they had developed diabetes after the age of 30 .

There are reports both on normal [15-19] and impaired $[12,13]$ left ventricular systolic function in patients with Type 1 diabetes at rest. In the present study left ventricular systolic function was normal in three of the four diabetic groups whereas an increased myocardial contractility was found in female patients with Type 2 diabetes similar to that reported recently by Thuesen et al. in Type 1 diabetes [41]. This is in contrast to our previous study on newly diagnosed patients with Type 2 diabetes in whom both systolic time intervals and echocardiography showed a depressed myocardial systolic function [27]. However, this might have been due to asymptomatic coronary heart disease or uncontrolled hyperglycaemia per se. At least systolic time intervals tended to be normalised after cor- 
rection of hyperglycaemia [42]. Despite a normal or even increased myocardial systolic function at rest an abnormal ejection fraction response to exercise was frequently observed in the present patient groups [43].

The present results showed abnormalities in left ventricular diastolic function in diabetic patients. The mean peak diastolic filling rate was lowered in male and female patients with Type 2 diabetes as well as in female patients with Type 1 diabetes. In addition, isovolumic relaxation period was prolonged particularly in patients with Type 2 diabetes. The more abnormal $\mathrm{A} / \mathrm{H}$-ratio in apexcardiography in our female patients with Type 2 diabetes reflects also an impaired diastolic compliance $[37,44]$. Thus, abnormalities attributable to diabetic heart muscle disease are not confined to Type 1 diabetes with long duration of diabetes, but they may be even more common in Type 2 diabetes. However, both the prolonged isovolumic relaxation period and impaired diastolic filling are non-specific findings, and they may be found in various diseases affecting heart muscle, including coronary heart disease and hypertension $[45,46]$. Since asymptomatic coronary heart disease may be present in middle-aged persons, particularly in diabetic patients, the contribution of silent ischaemia was evaluated by exercise electrocardiography, radionuclide angiocardiography and thallium scintigraphy. In asymptomatic patients with normal resting electrocardiograms these methods have been shown to be highly reliable to exclude silent coronary artery disease, but even thallium scintigraphy may give false negative results [47]. On the other hand, an increased fibrosis in diabetic myocardium may cause a perfusion defect in thallium scintigraphy in the absence of occlusive coronary artery disease [48]. In the present study coronary angiography was not performed because all patients were asymptomatic. Taking into account the limitations associated with all non-invasive methods to detect coronary heart disease, most of the diabetic patients with abnormalities in diastolic function showed no evidence of asymptomatic myocardial ischaemia. Thus, it is very unlikely that the observed abnormalities in diastolic function can be ascribed to coronary artery disease.

The present findings on diastolic abnormalities are in accordance with previous studies on patients with Type 1 [15-20] and Type 2 diabetes [28] carried out using echocardiography $[15-19,28]$ or radionuclide angiocardiography [20]. In contrast to some other studies $[16,19]$, the isovolumic relaxation period was normal in our patients with Type 1 diabetes, but the selection of patients for different studies can explain the divergent results in this respect.

In contrast to some echocardiographic studies [15-18], the impaired diastolic function was not associated with the duration of diabetes or the presence of retinopathy. Neither was there any relationship between glycaemic control and the peak diastolic filling rate. These findings agree with that reported recently by Kahn et al. [20] and Punzergruber et al. [19]. However, this does not mean that the control of hyperglycaemia would not be of importance in the prevention of left ventricular dysfunction in diabetes; but further prospective studies are needed to resolve this question.

In the present study, heart rate variation which reflects parasympathetic function [35] was lower in diabetic patients with abnormal diastolic filling rate than in those with normal filling. Furthermore, a significant, although low correlation was found between the peak diastolic filling rate and heart rate variation or the decrease in systolic blood pressure during orthostatic test. A similar association between the presence of autonomic neuropathy and diastolic filling abnormalities was found by Kahn et al. [20]. In that study there was a closer association between the impaired filling determined by radionuclide ventriculography and the decrease in systolic blood pressure than in our study. Kahn et al. found also that plasma norepinephrine levels were decreased in diabetic patients with abnormal filling. It is, however, far from clear whether autonomic neuropathy is the principal background factor of diastolic dysfunction; and other mechanisms may also be involved. These include accumulation of cholesterol and triglycerides in myocardial cells and glycoprotein in myocardial interstitium which may lead to a decrease in left ventricular compliance $[10,49,50]$. In addition, diabetic microangiopathy involving myocardium may be a contributing factor in this respect. Thus, Fisher and co-workers, [51] who reported an impaired left ventricular function on exercise in a group of subjects with long-standing Type 1 diabetes, performed endomyocardial biopsy on 8 of 16 patients with abnormal ejection fraction response and found arterial thickening and interstitial fibrosis in 5 patients, and basement membrane thickening in 2 patients.

Left ventricular mass/body surface area was increased in female patients with Type 2 diabetes in the present study. This finding is compatible with our previous study [27] and also with that reported by Pozzoli et al. on previously diagnosed diabetic patients [28]. The pathogenetic mechanisms of the observed left ventricular hypertrophy are not clear, but in addition to high blood pressure level, hyperinsulinaemia or metabolic abnormalities associated with it may be involved in the increase of left ventricular mass [52]. Left ventricular hypertrophy may lead to a diminished left ventricular compliance. In the present study left ventricular hypertrophy did not, however, account for the impaired diastolic filling in diabetic patients.

In conclusion, an impairment in left ventricular diastolic filling was common in both types of diabetic patients without evidence of any cardiovascular disease. This abnormality was associated with signs of autonomic neuropathy, but not to metabolic control of diabetes, the duration of diabetes, or the presence of retinopathy. This diastolic function abnormality may contribute to the high cardiac morbidity and mortality 
among diabetic patients; at least on occasions when it occurs concomitantly with coronary heart disease and hypertension, as is quite commonly the case with middle-aged and elderly diabetic patients.

Acknowledgements. This work was financially supported by grants from the Foundation of Aarne and Aili Turunen, Kuopio, the Finnish Foundation of Diabetes Research, Helsinki, the Finnish Foundation for Cardiovascular Research, Helsinki, the North Savo Regional Fund of Cultural Foundation, Kuopio, Finland and Nordisk Insulinfond, Copenhagen, Denmark.

\section{References}

1. Pyörälä K, Laakso M, Uusitupa M (1987) Diabetes and atherosclerosis: an epidemiologic view. Diabetes Metab Rev 3: 463-524

2. Rubler S, Dlugash J, Yuceoglu YZ, Kumral T, Branwood AW, Srishman A (1972) New type of cardiomyopathy associated with diabetic glomerulosclerosis. Am J Cardiol 30: 595-602

3. Hamby RJ, Zoneraich S, Sherman L (1974) Diabetic cardiomyopathy. JAMA 299: 1749-1754

4. Zoneraich S, Silverman G (1978) Myocardial small vessel disease in diabetic patients. In: Zoneraich S (ed) Diabetes and the heart. Charles C Thomas, Springfield Illinois, pp 3-28

5. Crall FV, Roberts WWC (1978) The extramural and intramural coronary arteries in juvenile diabetes mellitus. Am J Med 64: 221-230

6. Ledet $T$ (1968) Histological and histochemical changes in the coronary arteries of old diabetic patients. Diabetologia 4: 268-272

7. Ledet T (1972) Diabetic cardiopathy. Quantitative histological studies of the heart from young juvenile diabetics. Acta Pathol Microbiol Scand 84: 421-428

8. Fisher VW, Barner H, Leskiw L (1979) Capillary basal laminar thickness in diabetic myocardium. Diabetes 28: 713-719

9. Factor SM, Okun EM, Minase T (1980) Capillary microaneurysm in the human diabetic heart. N Engl J Med 302: 384-388

10. Regan TJ, Lyons MM, Ahmed SS, Levinson GE, Oldewarler HA, Ahmed MR, Haider B (1977) Evidence for cardiomyopathy in familial diabetes mellitus. J Clin Invest 60: 885-899

11. Kannel WB, Hjortland M, Castelli WP (1974) Role of diabetes in congestive heart failure. Am J Cardiol 34: 29-34

12. Friedman NE, Levitsky LL, Edidin DV, Vitullo DA, Lacina SJ, Chiemmongkolpit P (1982) Echocardiographic evidence for impaired myocardial performance in children with Type I diabetes mellitus. Am J Med 73: 846-851

13. Labakidi ZA, Goldstein DE (1983) High prevalence of echocardiographic abnormalities in diabetic youths. Diabetes Care 6: 18-22

14. Rubler S, Sajadi MRM, Araoye MA, Holford FD (1978) Noninvasive estimation of myocardial performance in patients with diabetes. Effect of alcohol administration. Diabetes 27: 127-134

15. Sanderson JE, Brown DDJ, Rivellese A, Kohner E (1978) Diabetic cardiomyopathy? An echocardiographic study of young diabetics. Br Med J 1: 404-407

16. Shapiro LM, Howat AP, Calter MM (1981) Left ventricular function in diabetes mellitus I: methodology and prevalence and spectrum of abnormalities. Br Heart J 45: 122-128

17. Shapiro LM, Leatherdale BA, Mackinnon J, Fletcher RF (1981) Left ventricular function in diabetes mellitus II: relation between clinical features and left ventricular function. $\mathrm{Br}$ Heart $\mathrm{J} 45$ : 129-132

18. Airaksinen J, Ikäheimo M, Kaila J, Linnaluoto M, Takkunen J (1984) Impaired left ventricular filling in young female diabetics. An echocardiographic study. Acta Med Scand 216: 509-516

19. Punzengruber C, Schernthaner G, Silberbauer K, Seebacker C (1986) Left ventricular function in well-controlled insulin-de- pendent (Type I) diabetics - an echophonocardiographic study. Cardiology 73: 132-138

20. Kahn JK, Zola B, Juni JE, Vinik AI (1986) Radionuclide assessment of left ventricular diastolic filling in diabetes mellitus with and without cardiac autonomic neuropathy. J Am Coll Cardiol 7: $1303-1309$

21. Ahmed SS, Jaferi GA, Narang RM, Regan TJ (1985) Preclinical abnormality of left ventricular function in diabetes mellitus. Am Heart J 89: 153-158

22. Zoneraich S, Zoneraich O, Rhee JJ (1977) Left ventricular performance in diabetic patients without clinical heart disease. Evaluation by systolic time intervals and echocardiography. Chest 72: 748-751

23. Seneviratne BIB (1977) Diabetic cardiomyopathy: the preclinical phase. Br Med J 1: 1444-1446

24. Rynkiewicz A, Semetkowska-Jurkiewicz E, Wyrzykowski B (1980) Systolic and diastolic time intervals in young diabetics. $\mathrm{Br}$ Heart J 44: 280-283

25. Dei Cas L, Zuliani U, Manca C, Zonca A, Bernardini B, Mansour M, Barilli AI (1980) Non invasive evaluation of left ventricular performance in 294 diabetic patients without clinical heart disease. Acta Diabetol Lat 17: 145-152

26. Posner J, Ilya R, Wanderman K, Weitzman S (1983) Systolic time intervals in diabetes. Diabetologia 24: 249-252

27. Uusitupa M, Siitonen O, Pyörälä K, Länsimies E (1985) Left ventricular function in newly diagnosed non-insulin-dependent (Type 2) diabetics evaluated by systolic time intervals and echocardiography. Acta Med Scand 217: 379-388

28. Pozzoli G, Vitolo E, Collini P, De Maria R, Castelli MR, Colombo $F$ (1984) Assessment of left ventricular function with M-mode echocardiography in a selected group of diabetic patients. Acta Diabetol Lat 21: 71-84

29. Shapiro LM (1984) A prospective study of heart disease in diabetes mellitus. QJ Med 209: 55 68

30. Laakso M, Rönnemaa T, Pyörälä K, Kallio V, Puukka P, Penttilä I (1988) Atherosclerotic vascular disease and its risk factors in non-insulin-dependent diabetics and nondiabetic subjects in Finland. Diabetes Care 11: 449-463

31. WHO Expert Committee on Diabetes Mellitus, WHO (1980) Second report. Geneva, No.646

32. Faber OK, Binder C (1977) C-peptide response to glucagon. A test for the residual beta cell function. Diabetes 26: 605-610

33. Rose GA (1962) The diagnosis of ischaemic heart pain and intermittent claudication in field surveys. Bull WHO 27: 645-658

34. Rose GA, Blackburn H (1968) Cardiovascular survey methods. WHO Monograph series 56, Geneva

35. Ewing DJ, Clarke BF (1982) Diagnosis and management of diabetic autonomic neuropathy. Br Med J 285: 916-918

36. Weissler AM, Harris WS, Schoenfeld CD (1969) Bedside technics for the evaluation of ventricular function in man. Am $J$ Cardiol 23: 577-583

37. Gibson TC, Madry R, Grossman N, McLaurin LP, Craig E (1974) The A wave of the apexcardiogram and left ventricular diastolic stiffness. Circulation 49: 441-446

38. Sahn DJ, DeMaria A, Kisslo J, Weyman A (1978) Recommendations regarding quantitation in $\mathrm{M}$-mode echocardiography: results of a survey of echocardiographic measurements. Circulation 58: 1072-1083

39. Griffiths CJ, Murray A, Hunter S (1982) Computer assisted Mmode echocardiogram analysis. Clin Phys Physiol Meas 3: 103-114

40. Penttilä IM, Voutilainen E, Laitinen P, Juutilainen P (1981) Comparison of different analytical and precipitation methods for the direct estimation of serum high-density lipoprotein cholesterol. Scand J Chem Lab Invest 41: 353-360

41. Thuesen L, Sandahl Christiansen J, Falstie-Jensen N, Christensen CK, Hermansen K, Mogensen CE (1985) Increased myocardial contractility in short-term Type 1 diabetic patients: an echocardiographic study. Diabetologia 28: $822-826$

42. Uusitupa M, Siitonen O, Aro A, Korhonen T, Pyörälä K (1983) 
Effect of correction of hyperglycemia on left ventricular function in non-insulin-dependent (type 2) diabetics. Acta Med Scand 213: $363-368$

43. Mustonen J, Uusitupa M, Tahvanainen K, Talwar S, Laakso M, Länsimies E, Kuikka J, Pyörälä K (1988) Impaired left ventricular systolic function during exercise in middle aged insulin-dependent and non-insulin-dependent diabetic subjects without clinically evident cardiovascular disease. Am J Cardiol (in press)

44. Woight GC, Friesinger GC (1970) The use of apexcardiography in the assessment of left ventricular diastolic pressure. Circulation 41: 1015-1024

45. Upton MT, Gibson DG, Brown DJ (1976) Echocardiographic assessment of abnormal left ventricular relaxation in man. Br Heart J 38: 1001-1009

46. Chen W, Gibson D (1979) Relation of isovolumic relaxation to left ventricular wall movement in man. Br Heart J 42: 51-56

47. Berman DS, Rozanski A, Knoebel SB (1987) The detection of silent ischemia: cautions and precautions. Circulation 75: 101-105

48. Genda A, Mizuno S, Nunoda S, Nakayma A, Igarashi Y, Sugihara N, Namura M, Takeda R, Bunko H, Hisada K (1986) Clinical studies on diabetic myocardial disease using exercise testing with myocardial scintigraphy and endomyocardial biopsy. Clin Cardiol 9: 375-382
49. Regan TJ, Weisse AB (1978) The question of cardiomyopathy in diabetes mellitus. Ann Int Med 89: 1000-1002

50. Ledet T, Neubauer B, Christensen NJ, Lundbeck K (1979) Diabetic cardiopathy. Diabetologia 16: 207-209

51. Fisher BM, Gillen G, Lindop GBM, Dargie HJ, Frier BM (1986) Cardiac function and coronary arteriography in asymptomatic Type 1 (insulin-dependent) diabetic patients; evidence for a specific diabetic heart disease. Diabetologia 29: 706-712

52. Uusitupa M, Siitonen O, Pyörälä K, Mustonen J, Voutilainen E, Hersio K, Penttilä I (1987) Relationship of blood pressure and left ventricular mass to serum insulin levels in newly diagnosed non-insulin-dependent (Type 2) diabetic patients and in nondiabetic subjects. Diabetes Res 4: 19-25

Received: 25 April 1988

and in revised form: 2 September 1988

Dr. M.Uusitupa

Kuopio University Central Hospital

SF-70210 Kuopio

Finland 